spinal needle. The appearance of neurologic symptoms like sudden headache in patients undergoing epidural or spinal anaesthesia suggests the possibility of pneumocephalus.

\section{TAYLOR'S APPROACH TO SUBARACHNOID BLOCK IN AN ELDERLY PATIENT: A SOLUTION AFTER FAILED CONVENTIONAL APPROACH}

D Gonçalves, D Roriz ${ }^{*}$, F Teixeira, JM Cardoso, AP Pereira, C Sampaio. Centro Hospitalar Trás-os-Montes e Alto Douro, Vila Real, Portugal

\subsection{6/rapm-2021-ESRA.65}

Background and Aims The execution of spinal anesthesia in elderly patients can be difficult due to several anatomical degenerative alterations.

Taylor's approach for neuraxial anesthesia is a safe, yet rarely used, alternative with a high success rate and might be useful specially in elderly.

Methods A 92-year-old female patient, ASA III, was scheduled for an urgent dynamic hip screw after left trochanteric fracture. After obtaining informed consent, an ultrasound-guided fascia Iliaca block was performed with $30 \mathrm{ml}$ of $0,25 \%$ Levobupivacaine.

Subarachnoid block, using 27G and 25G Quincke ${ }^{\circledR}$ needle, with the median and paramedian approach was attempted unsuccessfully by two anesthetists at the level of L2-L3, L3-L4 and L4-L5 as the needle hit bone in all directions.

We decided one last attempt using Taylor's approach and the spinal needle was inserted in a cephalo-medial direction, 1 $\mathrm{cm}$ medial and $1 \mathrm{~cm}$ caudally to the Posterior Superior Iliac Spine, the L5-S1 space was targeted and cerebrospinal fluid was obtained.

Results A satisfactory spinal block was achieved, which allowed surgery to proceed without complications. Patient's hemodynamics were stable throughout the entire procedure and no adverse events were registered in the intraoperative nor postoperative period.

Conclusions The L5-S1 intervertebral space is usually the biggest one and targeting it (Taylor's approach) might be useful in patients with degenerative changes as it may present an easier way to reach the subarachnoid space.

\section{SPINAL ANESTHESIA IN LAPAROSCOPIC CHOLECYSTECTOMY IN A PATIENT WITH CONGESTIVE HEART FAILURE WITH REDUCED EJECTION FRACTION}

N Jargalsaikhan*, B Shiiter, U Ganbaatar. The Third State Central Hospital, Ulaanbaatar, Mongolia

\subsection{6/rapm-2021-ESRA.66}

Background and Aims Laparoscopic cholecystectomy (LC) is relatively common procedure which is generally performed under general anesthesia. However in some specific cases, regional anesthesia can be considered as a good choice for patients who are poor candidates for general anesthesia due to comorbidities. In this case we present laparoscopic cholecystectomy under spinal anesthesia successfully performed in patient with anesthetic problems include HFrEF and COPD

Methods A 68-year old, ASA III male patient underwent laparoscopic cholecystectomy. He had been diagnosed COPD, and heart failure with ACC/AHA stage III, NYHA score IIIa. He is

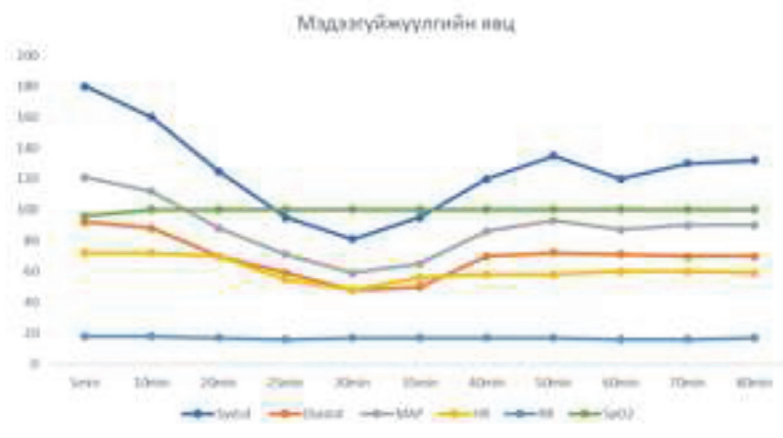

Abstract 66 Figure 1

former smoker and overweighed. He had coronary revascularization 10 years ago. In echocardiography septal hypokinesia, left ventricle dilation with $3,8 * 1,6 \mathrm{~cm}$ thrombus in anterior wall of left ventricle. EF was 33\%. On ECG heart rate was 78 bpm with Q wave and negative $\mathrm{T}$ wave on V3-V6 leads. Cardiology consultation reported a postoperative risk of $7 \%$ based on modified Goldman cardiac risk criteria.

Results Upon arrival at the operating room routine monitoring was established. Patient sat upright position and 27G spinal needle was used to enter the subarachnoid space at the T10T11 intervertebral space under complete aseptic technique. Hyperbaric bupivacaine $0.5 \% 2 \mathrm{ml}, \quad 0.005 \% \quad 0.4 \mathrm{ml}$ was injected so that a sensory loss up to T3 dermatome was achieved. LC was smooth and uneventful

Conclusions Patients with very low EF\% are considered to be high risk for general anesthesia due to irregular heartbeat. Spinal anesthesia can be safe anesthetic method to be used in patient with advanced cardiopulmonary disease by experienced and qualified anesthesiology team.

\section{SUBARACNOID BLOCK WITH LUMBAR ULTRASOUND IN GERIATRIC PATIENTS: PRELIMINARY STUDY RESULTS}

AS Sahin*, S Özkan, A Temizyürek. SBU Kanuni Sultan Suleyman Education and Training Hospital, Istanbul, Turkey

\subsection{6/rapm-2021-ESRA.67}

Background and Aims We aimed to evaluate the benefit of lumbar ultrasonography in predicting the needle depth before the block and determining the most appropriate entry point in geriatric patients.

Methods Twenty geriatric patients who were to undergoTUR$\mathrm{P} / \mathrm{M}$ operation with subarachnoid block were received to study after hospital ethics committee. Lumbar ultrasonography was performed to determine the L3-L5 interspinous space by same anesthesiologist in sitting position. The distances between skinsubdural distance were measured in both sagittal and transverse planes. The distance reached by needle after procedure and the duration of procedure were measured.

Results The mean age of the patients was 69.4, height 166.1 $\mathrm{cm}$, and weight $73.9 \mathrm{~kg}$. Thirteen were men and seven were women. Twelve patients with ASA-II, 8 patients with ASA-III The probe was used as transverse in half of the patients and sagittal in half. The procedure time was 3.3, the distance measured by USG was $5.09 \mathrm{~cm}$, and the applied needle distance was $5.66 \mathrm{~cm}$. The results were considered to be correlated between the distance measured by USG and the distance measured with the needle. There was no difference between 